Rusanova O, Wang Waylung. Modern bases of control for functional provision of special work capacity in skilled athletes. Theory and Methods of Physical education and sports. 2019; 1 : $42-46$

DOI:10.32652/ tmfvs.2019.1.42-46
Русанова О, Ван Вейлун. Сучасні основи контролю функціонального забезпечення спеціальної роботоздатності кваліфікованих спортсменів. Теорія і методика фрізичного виховання і спорту 2019; 1: 42-46 DOI:10.32652/tmfvs.2019.1.42-46.

\title{
СУЧАСНІ ОСНОВИ КОНТРОЛЮ ФУНКЦІОНАЛЬНОГО ЗАБЕЗПЕЧЕННЯ СПЕЦАЛЬНОЇ РОБОТОЗДАТНОСТІ КВАЛІФІКОВАНИХ СПОРТСМЕНІВ
}

\section{Ольга Русанова, Ван Вейлун}

Національний університет фізичного виховання і спорту України Київ, Україна

Анотація. У системі підготовки спортсменів у циклічних видах спорту, зокрема у веслуванні академічному та веслуванні на байдарках і каное, контроль розглядають як інтегрований компонент системи управління тренувальним процесом. Реалізація його як фрункції управління дозволяє сфформувати систему оцінювання спеціальних фрункціональних можливостей, за допомогою якої спортсмени та тренери можуть отримати об'єктивну інформацію не тільки про поточний рівень можливостей, а й виробити підстави для фформування спеціалізованої спрямованості тренувального процесу. У видах веслувального спорту існує проблема визначення й обліку індивідуальних параметрів навантажень, які впливають на розвиток компонентів структури фрункціонального забезпечення спеціальної роботоздатності. Вирішення цієї проблеми є вагомим чинником індивідуалізації спеціальної фізичної підготовки спортсменів.

Мета. Вивчити питання про сучасні концепції контролю функціонального забезпечення спеціальної роботоздатності кваліфрікованих спортсменів. Методи. Аналіз, систематизація, узагальнення даних літературних джерел. Результати. На основі аналізу, систематизації та узагальнення даних літературних джерел представлено концепції кількісної оцінки тренувальних навантажень, що можуть використовуватися для моніторингу у тренувальному процесі кваліфікованих спортсменів-веслувальників. Це точне кількісне визначення виконуваних тренувальних навантажень створює передумови для ефективної реалізації запланованої підготовки веслувальників, моніторингу фрактично виконаної тренувальної роботи та проведення аналізу індивідуальних реакцій на навантаження кожного конкретного спортсмена, що дозволяє прогнозувати зміни роботоздатності.

У процесі моніторингу тренувальних навантажень у циклічних видах спорту з проявами витривалості під час виконання тривалої роботи субмаксимальної інтенсивності кількісне визначення навантаження проводять за допомогою розрахунку тренувального імпульсу, кількісної оцінки навантаження Lusia's TRIMP «час-у-зоні», оцінки рівня сприйнятого напруження навантаження за методом Session-RPE ma T2 minute методу, запропонованого австралійськими дослідниками.

Виявлено, що ключем до успіху для кваліфрікованих спортсменів є ретельне планування та використання сучасних концепцій для ефективного контролю та моніторингу навантажень під час занять.

Ключові слова: веслування, кількісна оцінка, навантаження, моніторинг, облік.

\section{Olha Rusanova, Wang Waylung MODERN BASES OF CONTROL FOR FUNCTIONAL PROVISION OF SPECIAL WORK CAPACITY IN SKILLED ATHLETES}

\begin{abstract}
In the system of training athletes of cyclic sports events, such as rowing, kayaking and canoeing, control is considered as an integrated component of the system of training process management. Its realization as a management function allows to form a system of evaluation of special functional capabilities, through which athletes and coaches can obtain objective information not only about the current level of capacities, but also create the basis for the formation of a specialized focus of the training process. In rowing sports events, there is the problem of determining and accounting individual load parameters that influence the development of components of the structure of special work capacity functional provision. Solving this problem is a significant factor in the individualization of special physical training of athletes. Objective. To study the issue of modern concepts of control for the functional provision of special work capacity of qualified athletes. Methods. Analysis, systematization, generalization of the data of literary sources. Results. On the basis of analysis, systematization and generalization of the data of literary sources, concepts of quantitative assessment of training loads that can be used for monitoring in the training process of qualified rowers have been presented. This precise quantitative determination of the exercised training loads creates the prerequisites for the effective implementation of the planned training of rowers, monitoring of the actual training work and conducting an analysis of individual responses to the load of each particular athlete, which allows predicting changes in work capacity.

In the process of monitoring the training loads in cyclic sports events with endurance manifestations during prolonged work of submaximal intensity, quantitative determination of the load is carried out by calculating the training pulse, quantifying the load time of the Lusia"s TRIMP "time-in-zone", estimating the level of perceived stress on the Session-RPE method and T2 minute method proposed by Australian researchers.
\end{abstract}

The key to success for skilled athletes is the thorough planning and use of modern concepts for effective control and monitoring of loads during training sessions.

Keywords: rowing, quantitative assessment, loads, monitoring, account. 
Вступ. У системі підготовки спортсменів у циклічних видах спорту, зокрема у веслуванні академічному та веслуванні на байдарках і каное, контроль розглядають як інтегрований компонент системи управління тренувальним процесом. Реалізація його як функції управління дозволяє сформувати систему оцінки спеціальних функціональних можливостей, за допомогою якої спортсмени та тренери можуть отримати об'єктивну інформацію не тільки про поточний рівень можливостей, а й виробити підстави для формування спеціалізованої спрямованості та індивідуалізації спеціальної фізичної підготовки [1].

Таким чином, якість побудови тренувального процесу обумовлюється контролем та обліком тренувальних та змагальних навантажень. Загальне уявлення про обсяг таких навантажень у веслуванні академічному створюється на основі показників сумарного обсягу виконаної роботи у кілометрах, годинах, кількості тренувальних днів, загальної кількості тренувальних занять, кількості змагань та стартів. Важливим компонентом системи обліку та контролю тренувальних навантажень є сумарний обсяг виконаної роботи переважної спрямованості на розвиток різних рухових якостей. Тренувальні вправи, що їх розвивають, розподіляють на групи залежно від умов їх виконання та методів, додаткових засобів. Зважаючи на перераховані показники, можна дати характеристику навантаженням, що використовуються у різних структурних утвореннях тренувального процесу [3, 4].

На сучасному етапі під час підготовки спортсменів високого класу у веслуванні академічному необхідно орієнтуватися на засоби та методи, що забезпечують адекватність тренувальних впливів за характером та глибиною змін у діяльності функціональних систем, динамічною та кінематичною структурою рухів у процесі ефективної змагальної діяльності [4].

Тренувальні плани на певний період забезпечують основу для цього процесу, інтегруючи терміни та спрямованість тренування з метою досягнення цільового рівня ефективності в певний момент часу (наприклад, чемпіонати світу, Олімпійські ігри) [11, 13]. Це точне кількісне визначення виконуваних тренувальних навантажень створює передумови для ефективної реалізації запланованої підготовки веслувальників, моніторингу фактично виконаної тренувальної роботи та проведення аналізу індивідуальних реакцій на навантаження кожного конкретного спортсмена, що дозволяє прогнозувати зміни роботоздатності [6, 8, 13$]$.

Мета дослідження - вивчити питання про сучасні концепції контролю функціонального забезпечення спеціальної роботоздатності кваліфікованих спортсменів у порогових зонах енергозабезпечення у веслуванні академічному та веслуванні на байдарках і каное.

Методи дослідження: аналіз, систематизація, узагальнення даних літературних джерел.
Результати дослідження та їх обговорення. Дослідження є частиною науково-дослідної роботи, проведеної Національним університетом фізичного виховання і спорту України відповідно до плану НДР НУФВСУ на 2016-2020 рр. 3 теми «Побудова тренувального процесу висококваліфікованих спортсменів, які спеціалізуються у водних видах спорту, з урахуванням вимог змагальної діяльності» (номер держреєстрації 0116U001614).

Величину і спрямованість тренувальних і змагальних навантажень визначають за особливостями застосування та порядком поєднання таких компонентів: тривалість і характер окремих вправ; інтенсивність роботи під час виконання вправ; тривалість і характер пауз між окремими повтореннями. На основі вказаних компонентів у цілому дослідники виділяють окремі зони інтенсивності тренувальної роботи, характеристика яких дозволяє управляти тренувальним процесом [1-4].

У практиці веслування академічного та на байдарках i каное вітчизняні науковці виділяють п'ять зон інтенсивності роботи на основі дослідження індивідуальних особливостей прояву стомлення організму спортсменів у спеціальних тестових вправах [1, 2].

Виконання тренувальної роботи певного обсягу в різних зонах інтенсивності, поєднання ефектів тренувальних занять різного обсягу, інтенсивності та тривалості призводять до розвитку стомлення організму і потребують певного відновлення. Ефективне поєднання станів стомлення і відновлення в тренувальному процесі $€$ основою для збільшення функціональних можливостей організму і зростання тренованості спортсменів [1-4].

Під час виконання тренувального навантаження зазвичай враховують показники оперативної фізіологічної відповіді (наприклад, частота серцевих скорочень (ЧСС) або сприйняття спортсменами тренувального навантаження (наприклад, рівень сприйнятого напруження (Session-RPE)).

У процесі моніторингу тренувальних навантажень у циклічних видах спорту з проявами витривалості під час виконання безперервної роботи субмаксимальної інтенсивності кількісне визначення навантаження проводять за допомогою тренувального імпульсу Баністера (TRIMP) [6, 13]. Реалізація цього методу можлива тільки за умови використання сучасних пульсометрів. Тренувальний імпульс (TRIMP) - це розрахунковий показник за характеристиками реакції ЧСС при стандартній роботі. Його можна визначити за формулою:

TRIMP $=\mathrm{y} \times$ тривалість тренувального навантаження (хв) × (середнє ЧСС роботи ЧСС спокою) / (ЧСС макс. - ЧСС спокою),

де у - ваговий коефіцієнт.

Ряд авторів $[6,10,13,18]$ підтвердили валідність та надійність тренувального імпульсу Баніс- 
тера для моделювання спортивної продуктивності. Не зважаючи на це, метод піддавали критиці [5] за використання вагового коефіцієнта, специфічного для статі, для масштабування інтенсивності навантаження.

Пізніше італійські дослідники запропонували новий підхід до кількісного оцінювання навантаження Lusia's TRIMP «час-у-зоні», що визначає навантаження на основі обліку тривалості виконуваної роботи в трьох тренувальних зонах з індивідуальними специфічними фізіологічними параметрами, що визначаються для кожної зони [13, 15].

У практиці спортивного тренування використовують кілька порогових точок як для оцінювання функціональної підготовленості, так і для визначення спрямованості й інтенсивності навантаження [2, 13, 15]. За першого приросту концентрації лактату в крові виділяється перша порогова точка - вентиляційний (аеробний) поріг (VT) [2]. Багато досліджень демонстрували присутність другого підвищення вентиляції протягом навантаження зростаючої потужності в точці початку дихальної компенсації (RCP) - точки дихальної компенсації метаболічного ацидозу (RCMA). RCP відмічається під час появи гіпервентиляції («дихальної компенсації») .протягом навантаження зростаючої потужності. Ї̈̈ фізіологічне значення ще повністю не вивчене, але саме загальне пояснення цього явища - «вичерпання» буферних механізмів, - яке призводить до метаболічного ацидозу [2]. Отже, учені [1, 13, 15] відмічають другу контрольну точку в підвищенні реакції легеневої вентиляції (другий вентиляційний поріг або RCP) під час робочого навантаження 85-90 \% $\dot{\mathrm{VO}}_{2} \max$. Інтенсивність у $\mathrm{RCP}$, встановлена під час тестування висококваліфікованих спортсменів, становить $\left(91,8 \%\right.$ ЧСС $_{\max }$ i $\left.87,5 \% \dot{V O}_{2} \max \right)$. Вище даної точки починається так звана фаза III - активне виробництво молочної кислоти з подальшим накопиченням лактату крові та вентиляційною компенсацією [15].

Навантаження Lusia's TRIMP обчислюють за формулою, що грунтується на значеннях ЧСС (з 5-секундним інтервалом вимірювання), враховуючи індивідуалізовані зони інтенсивності на основі визначення індивідуального рівня ЧСС у VT i RCP [15]:

Lusia's TRIMP $=(1 \times$ Тривалість роботи у 30ні до рівня VT $)+(2 \times$ Тривалість роботи у зоні $\mathrm{V} / \mathrm{RCP})+(3 \times$ Тривалість роботи у зоні вище рівня RCP).

Альтернативно деякі дослідники заявили про свою підтримку Session-RPE методу [10, 13], що визначає рівень сприйнятого напруження навантаження спортсменом під час виконання перервної роботи чи роботи з додатковим обтяженням під час тренування [12, 13].

Методика пройшла апробацію 3 використанням он-лайн системи, яка складалася 3 анкети, в яку заносили дані про рівень сприйнятого напру-
Таблиця 1 - Характеристика зон інтенсивності у веслуванні академічному

\begin{tabular}{|c|l|c|c|l|}
\hline T-зона & \multicolumn{1}{|c|}{ La } & чCC $_{\max }, \%$ & $\begin{array}{c}\dot{\mathrm{V}}_{2} \mathrm{max} \\
\%\end{array}$ & \multicolumn{1}{|c|}{ RPE } \\
\hline T1 & нижче LT1 & $60-75$ & $<60$ & дуже легко \\
\hline T2 & $\begin{array}{l}\text { нижня половина } \\
\text { між LT1 і LT2 }\end{array}$ & $72-84$ & $60-72$ & легко \\
\hline T3 & $\begin{array}{l}\text { верхня половина } \\
\text { між LT1 і LT2 }\end{array}$ & $82-89$ & $70-82$ & важкувато \\
\hline T4 & LT2 & $88-93$ & $80-85$ & важко \\
\hline T5 & Вище LT2 & $92-100$ & $85-100$ & дуже важко \\
\hline
\end{tabular}

Примітки: ЧСС max $_{-}$відносна максимальна частота серцевих скорочень, \%;

$\dot{\mathrm{V}} \mathrm{O}_{2} \max$ - відносне максимальне споживання кисню, \%;

$\mathrm{RPE}$ - рейтинг сприйнятого навантаження, довільні одиниці;

LT1 - поріг лактату 1, стійке підвищення концентрації лактату під час навантаження;

LT2 - поріг лактату 2, верхня межа рівноваги між виробництвом лактату і лактатним кліренсом.

ження навантаження під час тренування на основі 10-бальної шкали CR-10 [10]. В ході анкетування спортсмени вказували тривалість навантаження (у хвилинах) для кожного тренування в певний день. Потім Session-RPE навантаження обчислювали як тривалість сеансу RPE × тривалість навантаження $[10,13]$. Відповідно до правил он-лайн системи, спортсмени щовечора заповнювали відповідну анкету .

Австралійські дослідники запропонували для кількісного оцінювання навантаження застосовувати Т2 minute метод, в основі якого лежить підхід до визначення часу в певній зоні для кількісного визначення навантаження, аналогічний раніше запропонованим методам [10, 13, 15]. Зони інтенсивності тренування (Т-зони) визначають стандартизованою фізіологічною номенклатурою, яка була створена в Австралійському інституті спорту [9, 13] (табл. 1).

Навантаження в кожній Т-зоні - це сума добутків тривалості роботи в цій зоні інтенсивності (визначається за ваговим коефіцієнтом для цієї зони) і специфічного для режиму зважування коефіцієнта для режиму тренування:

T2 (хвилинне навантаження) $=L_{\mathrm{T} 1}+L_{\mathrm{T} 1,5}+$

$$
\begin{aligned}
+L_{\mathrm{T} 2}+L_{\mathrm{T} 2,5} & +L_{\mathrm{T} 3}+\mathrm{T} L_{\mathrm{T} 3,5}+L_{\mathrm{T} 4}+L_{\mathrm{T} 4,5}+ \\
& +\mathrm{T}_{\mathrm{T} 5}+\mathrm{T}_{\mathrm{T} 6},
\end{aligned}
$$

де

$$
L \mathrm{~T} x x=D x \times F m \times F i(x),
$$

де $L \mathrm{~T} x$ - навантаження в зоні інтенсивності $x$ (Т2 хв); $D x$ - тривалість навантаження в зоні інтенсивності $x$ (min); $F m$ - ваговий коефіцієнт режиму тренування (безлімітний); $F i(x)=$ ваговий коефіцієнт інтенсивності в зоні $x$.

Вагові коефіцієнти для режиму тренування i зона інтенсивності Т2 min методу: 
- вагові коефіцієнти режиму тренування: веслування на воді - 1.00; веслувальний ергометр 1.35 ; дорожній велосипед - 0,80; стаціонарний велосипед $-0,95$; біг -1.40 ; плавання -1.20 ; ходьба - 0,50;

- ваговий коефіцієнт у зоні інтенсивності тренування: Т1 - 0,90; Т1.5 - 0,95; Т2 - 1.00; Т2.51.15 ; T3 - 1.35; T3.5 - 1.60; T4 - 2.10; T4.5-3.00; Т5 - 5.00; Т6 - 9.00.

У видах веслувального спорту існує проблема визначення й обліку індивідуальних параметрів навантажень, які впливають на розвиток компонентів структури функціонального забезпечення спеціальної роботоздатності, вирішення цієї проблеми є вагомими чинником індивідуалізації спеціальної фізичної підготовки у видах веслувального спорту.

3 розвитком мікротехнологій багато пристроїв широко використовують у спортивній індустрії для моніторингу інтенсивності навантаження. Монітори серцевого ритму (ЧСС), системи глобального позиціонування (GPS), акселерометри - невеликий їх перелік, що можуть надати тренерам дуже докладну інформацію про зовнішню (наприклад, показники відстані, швидкості човна) i внутрішню (наприклад, показники ЧСС, електрокардіографія в реальному часі, варіабельність ЧСС) складову навантаження. Незважаючи на те що пристрої, що використовуються на кожному занятті, дають можливість тренеру відстежувати точну інформацію, вони мають ряд недоліків, таких як висока вартість, вимоги до високої технічної кваліфікації і ризик втрати даних через технічну помилку.

Метод, що дозволяє зафіксувати рівень сприйнятого напруження навантаження, є дуже цікавим рішенням, і він був запропонований як простий, неінвазивний і недорогий метод моніторингу навантаження.

Новизна методу кількісного визначення виконуваних тренувальних навантажень Т2 min полягає у інтеграції трьох його компонентів у цілісну структуру, що поєднує суб'єктивні критерії оцінювання навантаження з включенням вагового коефіцієнта режиму тренування, який дозволяє характеризувати виконувану веслувальниками роботу у різних режимах до еквіваленту веслування на воді.

Висновки. Представлено концепції кількісного оцінювання тренувальних навантажень, що можуть використовуватися для моніторингу кожного конкретного тренувального заняття кваліфікованих спортсменів. Безумовно, ключем до успіху для кваліфікованих спортсменів є ретельне планування та використання сучасних концепцій для ефективного контролю й моніторингу навантажень під час занять. Результати вказують, що дослідження в цьому напрямі мають певні перспективи.

Конфлікт інтересів. Автори заявляють, що відсутній будь-який конфлікт інтересів.

\section{Література}

1. Дьяченко АЮ. Совершенствование специальной выносливости квалифицированных спортсменов в академической гребле. Киев: НПФ “Славутич-Дельфин”; 2004. 338 с.

2. Мищенко ВС. Функциональные возможности спортсменов. Киев: Здоров'я; 1990. 200 с.

3. Платонов ВН. Система подготовки спортсменов в олимпийском спорте. Общая теория и ее практические приложения : учебник : в 2 кн. Киев: Олимп. лит.; 2015. 1432 с.

4. Платонов ВН. Периодизация спортивной тренировки. Общая теория и ее практическое применение. Киев: Олимп. лит.; 2013. 624 с.

5. Akubat I, Patel E, Barrett S, Abt G. Methods of monitoring the training and match load and their relationship to changes in fitness in professional youth soccer players. J Sports Sci. 2012; 30(14):1473-1480.

6. Banister EW, Calvert TW, Savage MV, Bach T. A systems model of training for athletic performance. Austr J Sports Med. 1975; 7(3):57-61.

7. Beaver WL, Wasserman K, Whipp BJ. A new method for detecting anaerobic threshold by gas exchange. J Appl Physiol. 1986;60(6):2020-2027.

8. Borresen J, Lambert MI. Quantifying training load: A comparison of subjective and objective methods. Int J Sports Physiol Per. 2008;3(1):16-30.

9. Bourdon P. Blood lactate thresholds: Concepts and applications. In R. Tanner \& C. Gore (Eds.). Physiological tests for elite athletes. Champaign, IL: Human Kinetics. 2013: 77-102.

10. Foster C, Florhaug J A, Franklin J, Gottschall L, Hrovatin LA, Parker S, Dodge C. A new approach to monitoring exercise training. J Strength Cond R. 2001;15(1):109-115.

11. Fry RW, Morton AR, Keast D. Periodisation of training stress - A review. Can J Sports Sci. 1992;17(3):234-240.

12. Impellizzeri FM, Rampinini E, Coutts AJ, Sassi A, Marcora SM. Use of RPE-based training load in soccer. Med Sci Sports Ex. 2004;36(6): 1042-1047.

13. Jacqueline T, Anthony JR, Luana CM, Paul BG. Convergent validity of a novel method for quantifying rowing training loads. J Sports Sci. 2015; 33:3: 268-276.

14. Laukkanen RM, Virtanen PK. Heart rate monitors: State of the art. J Sports Sci. 1998; 16 (Suppl 1): 3-7.

15. Lucia A, Hoyos J, Santalla A, Earnest C, Chicharro J. Tour de France versus Vuelta a Espana: Which is harder? Med Sci Sports Ex. 2003;35(5):872-878. 
16. Morton RH, Fitz-Clarke JR, Banister EW. Modeling human performance in running. J Appl Physiol. 1990;69(3):11711177.

17. Scott BR, Lockie RG, Knight TJ, Clark AC, De Jonge XA. A comparison of methods to quantify the inseason training load of professional soccer players. Int J S Physiol \& Perf. 2013;8(2):195-202.

18. Sweet TW, Foster C, McGuigan MR, Brice G. Quantitation of resistance training using the session rating of perceived exertion method. J Str Cond Res. 2004;18(4):796-802.

19. Wallace LK, Slattery KM, Coutts AJ. A comparison of methods for quantifying training load: Relationships between modelled and actual training responses. Eur J Appl Physiol. 2014;114(1):11-20.

\section{Literature}

1. Dyachenko AY. Improving special endurance of skilled rowers. Kiev: NPF "Slavutich-Delfin"; 2004. 338 p.

2. Mishchenko VS. Functional opportunities of athletes. Kiev: Zdorovia; 1990. 200 p.

3. Platonov VN. System of athletes' preparation in the Olympic sport. General theory and its practical applications : textbook [for coaches] : in 2 books. Kiev: Olimpiyskaya literatura; 2015. 1432 c.

4. Platonov VN. Sports training periodization. General theory and its practical applications. Kiev: Olimpiyskaya literatura; 2013. 624 p.

5. Akubat I, Patel E, Barrett S, Abt G. Methods of monitoring the training and match load and their relationship to changes in fitness in professional youth soccer players. J Sports Sci. 2012; 30(14):1473-1480.

6. Banister EW, Calvert TW, Savage MV, Bach T. A systems model of training for athletic performance. Austr J Sports Med. 1975; 7(3):57-61.

7. Beaver WL, Wasserman K, Whipp BJ. A new method for detecting anaerobic threshold by gas exchange. J Appl Physiol. 1986;60(6):2020-2027.

8. Borresen J, Lambert MI. Quantifying training load: A comparison of subjective and objective methods. Int J Sports Physiol Per. 2008;3(1):16-30.

9. Bourdon P. Blood lactate thresholds: Concepts and applications. In R. Tanner \& C. Gore (Eds.). Physiological tests for elite athletes. Champaign, IL: Human Kinetics. 2013: 77-102.

10. Foster C, Florhaug J A, Franklin J, Gottschall L, Hrovatin LA, Parker S, Dodge C. A new approach to monitoring exercise training. J Strength Cond R. 2001;15(1):109-115.

11. Fry RW, Morton AR, Keast D. Periodisation of training stress - A review. Can J Sports Sci. 1992;17(3):234-240.

12. Impellizzeri FM, Rampinini E, Coutts AJ, Sassi A, Marcora SM. Use of RPE-based training load in soccer. Med Sci Sports Ex. 2004;36(6): 1042-1047.

13. Jacqueline T, Anthony JR, Luana CM, Paul BG. Convergent validity of a novel method for quantifying rowing training loads. J Sports Sci. 2015; 33:3: 268-276.

14. Laukkanen RM, Virtanen PK. Heart rate monitors: State of the art. J Sports Sci. 1998; 16 (Suppl 1): 3-7.

15. Lucia A, Hoyos J, Santalla A, Earnest C, Chicharro J. Tour de France versus Vuelta a Espana: Which is harder? Med Sci Sports Ex. 2003;35(5):872-878. 1177.

16. Morton RH, Fitz-Clarke JR, Banister EW. Modeling human performance in running. J Appl Physiol. 1990;69(3):1171-

17. Scott BR, Lockie RG, Knight TJ, Clark AC, De Jonge XA. A comparison of methods to quantify the inseason training load of professional soccer players. Int J S Physiol \& Perf. 2013;8(2):195-202.

18. Sweet TW, Foster C, McGuigan MR, Brice G. Quantitation of resistance training using the session rating of perceived exertion method. J Str Cond Res. 2004;18(4):796-802.

19. Wallace LK, Slattery KM, Coutts AJ. A comparison of methods for quantifying training load: Relationships between modelled and actual training responses. Eur J Appl Physiol. 2014;114(1):11-20.

Надійшла 07.03.2019

\section{Інформація про авторів}

Русанова Ольга Михайлівна, https:orcid.org/ 0000-0001-7495-7030

rusanova2080@gmail.com

Ван Вейлун

https:orcid.org/0000-0002-4659-2270

rusanova2080@gmail.com

Національний університет фрізичного виховання і спорту України, 03150, Київ, вул. Фізкультури, 1
Information about the authors

Rusanova Olga, https:orcid.org/0000-0001-7495-7030 rusanova2080@gmail.com,

Wang Weilong https:orcid.org/0000-0002-4659-2270 rusanova2080@gmail.com,

National University of Ukraine on Physical Education and Sport, 03150, Kyiv, Fizkul'tury str., 1. 